\title{
IAQ in Conference Room whit Surveys
}

\author{
Katarzyna Gładyszewska-Fiedoruk ${ }^{1, *}$ \\ ${ }^{1}$ Bialystok University of Technology, Department of HVAC Engineering, 15-351 Białystok, Poland
}

\begin{abstract}
The work presents three basic air pollutants in the room, degrading the indoor air quality. The only source of pollution in the analysed room are people. The research was carried out in a building located in north-eastern Poland, in a temperate climate, in an area where the outside air is very clean. That is why air exchange is often carried out by opening windows (natural ventilation). That was also the case during the described experiment. In the room during the experiment there were 55 people, all of them doing the same physical activity, sitting work. The temperature and relative humidity of the air, the concentration of carbon dioxide in the room and the sound level were analysed. During the experiment, questionnaire surveys were also conducted. Respondents answered the same set of questions at the beginning and at the end of the meeting. The IAQ was low during measurements. Carbon dioxide concentration ranged from 1700-2000 ppm. The temperature was too low $\left(18-19^{\circ} \mathrm{C}\right)$. The smell for the respondents was not perceptible. The noise during measurements ranged within $50 \mathrm{~dB}$. It was a parameter that aroused the greatest dissatisfaction among the surveyed. They didn't pay attention to a low temperature.
\end{abstract}

\section{Introduction}

The task of HVAC systems is to maintain appropriate indoor conditions [1-4]. Central heating and refrigeration appliances (often with heating function) are designed to maintain the desired temperature. The parameter most identified by people $[5,6]$.

In order to reduce human exposure to pollution in rooms, an appropriate ventilation strategy should be provided. Such a strategy is even more important in naturally ventilated rooms, where is a small interchange of air exchange [7]. Another important issue is: which of the ventilation systems to use: natural or mechanical. Each of them have their own advantages and disadvantages. Mechanically ventilated buildings, reduce the concentration of PM2.5 dusts, and at the same time increase concentrations in $\mathrm{NO}_{2}$ rooms [8,9]. Although ventilation is very important, in some cases it may not provide the desired effects [10]. Improper ventilation can impair indoor air quality, although it is intended to reduce energy consumption [11].

Another important issue is the close relationship between indoor air quality and the energy efficiency of the building $[3,12,13]$. This is the main reason for saving ventilation outlays. This is the reason for using recirculation in general-purpose premises, where no special operations are carried out, and the only contaminants are from people and they are related to their physiology: relative humidity, temperature and $\mathrm{CO}_{2}$ [14].

Conference rooms have very uneven operation during the day, perhaps this is the reason for limiting financial outlays for ventilation installations [15].
The adaptive approach comes from field studies, aimed at analysing the real acceptability of the thermal environment, which strongly depends on the context, behaviour of people and their expectations [16-20]. In recent years, various authors have encouraged field studies to obtain more reliable information on the actual room conditions [17], [21-25].

Lack of thermal comfort over a longer period of time may be the basis of dysfunction of internal organs, which in turn lead to serious threats to life [26, 27].

The aim of the study is to analyse the air quality in the conference room. The temperature and relative humidity of the air as well as the concentration of carbon dioxide in the room where the only sources of pollution are people showing the same physical activity. In order to have a full picture of comfort in the room, questionnaires were analysed, to which the respondents answered at the beginning and at the end of the meeting. The sound level during the meeting was also analysed.

\section{Experimental research}

The research was carried out in Białystok in north-eastern Poland, in an area where the outside air is very clean. During the measurement period, the concentration of carbon dioxide in the outside air ranged between 360-400 ppm [18]. In the analysed room (fig. 1), only central heating and refrigeration appliances were installed from HVAC systems. There is no organized air exchange in this room. The cooling system causes the illusion of ventilation, because only the temperature is immediately identified by the users of the rooms. The authors of other

* Corresponding author: k.gladyszewska@pb.edu.pl

(C) The Authors, published by EDP Sciences. This is an open access article distributed under the terms of the Creative Commons Attribution License 4.0 
publications have reached similar observations $[1,6]$. The air quality in this room is very low. The HVAC system is controlled by thermostatic valves.

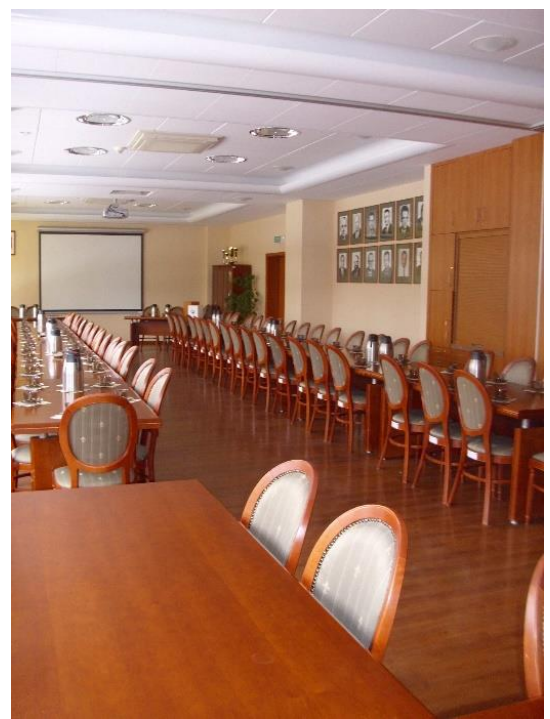

Fig. 1. Analysed conference room.

During the experiment, the air temperature, its relative humidity and the concentration of $\mathrm{CO}_{2}$ in the room were investigated. The noise measurements in the room were also carried out. The only source of pollution in the analysed room are people.

The meters are placed at a height of about $90 \mathrm{~cm}$ from the floor (the room is flat, there is no height for the speaker). It was assumed that this is the height on which the head of the participant is located. The meters are located at a distance from people (about $2 \mathrm{~m}$ ) to avoid the influence of the close proximity of the "sources" of pollution to instrument readings and in the case of sound measurement to avoid reflection or absorption.

Measurements of air parameters were made with Testo 435 recorder. Noise measurements was with the Testo 81505638155 recorder. The precision of the IAQ probe was as follows: temperature in the range between $20^{\circ} \mathrm{C}$ and $+50^{\circ} \mathrm{C}: \pm 0.3^{\circ} \mathrm{C}$, humidity in the range between +2 and $+98 \%$ RH: $\pm 2 \%$ RH, carbon dioxide concentration in the range between +0 and $+5000 \mathrm{ppm}$ $\mathrm{CO}_{2} \pm 3 \%$. The precision of the Testo 81505638155 recorder in the range of +32 to $+130 \mathrm{~dB}$ was $\pm 1 \mathrm{~dB}$. The frequency of recording the measurement made Testo 435 was $1 \mathrm{~min}$. The recorded result is the average of 30 samples. The sound level was recorded every $5 \mathrm{~min}$. The recorded result is the average of 150 samples.

After 20 minutes small windows were opened in the room and this way of ventilation was until the end of the experiment. At 13:38 one of the windows was closed. The exchange rate for the first 20 minutes is 0 , here are the most stable conditions of the experiment. Then for 65 minutes the number of exchanges is 9 . After this time, the exchange rate drops to 8.5 .

An error account was made according to [28]. The maximum measurement error was set at $7.3 \%$ for temperature measurements, $5.8 \%$ error for relative humidity measurements and $6.4 \%$ for $\mathrm{CO}_{2}$ concentration measurements. The sound level is subject to $5.1 \%$ error. Error bars are marked in Figs. 2-5.

During our research people taking part in conference room filled surveys on their air parameters and ventilation. 20 women and 20 men participated in our tests, fulfilled questionnaires. They judged their air parameters and ventilation at the start and at the end of conference proceedings. Not everyone present in the room answered the questions because they were busy with deliberations.

The questionnaire consisted of the following question: What do you think about? (Tab. 1).

Table 1. The questionnaire

\begin{tabular}{|l|l|l|l|l|l|}
\hline & $\begin{array}{l}\text { very } \\
\text { low }\end{array}$ & low & normal & high & $\begin{array}{l}\text { very } \\
\text { high }\end{array}$ \\
\hline Temperature & & & & & \\
\hline Humidity & & & & & \\
\hline Noise & & & & & \\
\hline Odors & & & & & \\
\hline IAQ & & & & & \\
\hline Ventilation & & & & & \\
\hline
\end{tabular}

\section{Results and discussion of results}

The measurement results are shown in figs. 2-5. Fig. 2 shows the temperature distribution, fig. 3 shows the course of the relative air humidity during the session, while fig. 4 shows the $\mathrm{CO}_{2}$ concentration in the room. Fig. 5 shows the noise level record during the meeting.

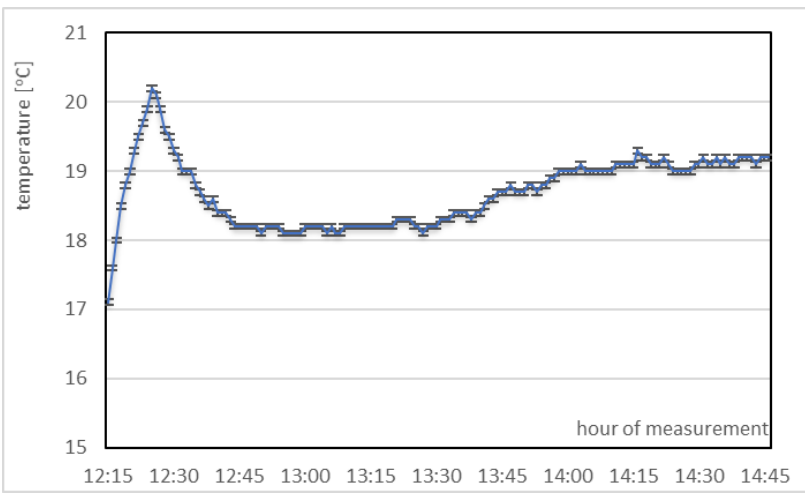

Fig. 2. Measured indoor temperature in analysed room.

During the deliberations in the room the temperature was too low (fig. 2) [29-31]. Relative humidity was in accordance with guidelines [29-31]. Concentration of $\mathrm{CO}_{2}$ at the beginning of the meeting was higher than recommended in the standards [29-31]. During the meeting was still growing, reaching the maximum value of $2007 \mathrm{ppm}$ at 14:40. Analysing fig. 2, it can be seen that the number of exchanges 9 would be sufficient for 55 people in the analysed Hall if the initial $\mathrm{CO}_{2}$ concentration was lower. If the traditional room before the deliberations was ventilated. The $\mathrm{CO}_{2}$ concentration at multiples of 9 is a straight line parallel to the time axis. There is no downward or upward trend. The number of exchanges at level 8.5 is too small for the analysed conditions. The $\mathrm{CO}_{2}$ concentration curve has an upward trend. 


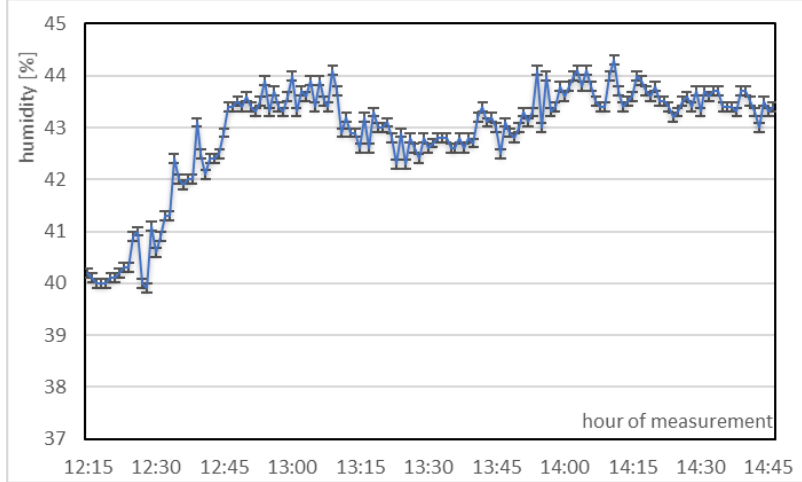

Fig. 3. Measured indoor relative humidity in analysed conference room.

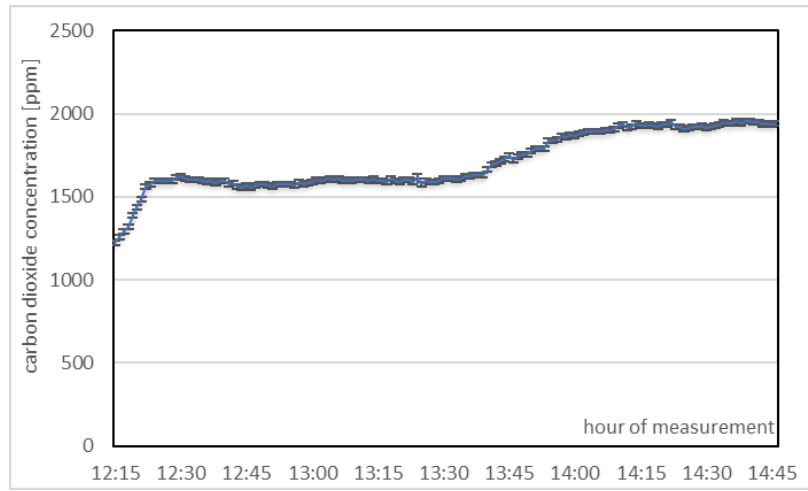

Fig. 4. Measured indoor carbon dioxide concentration in analysed conference room.

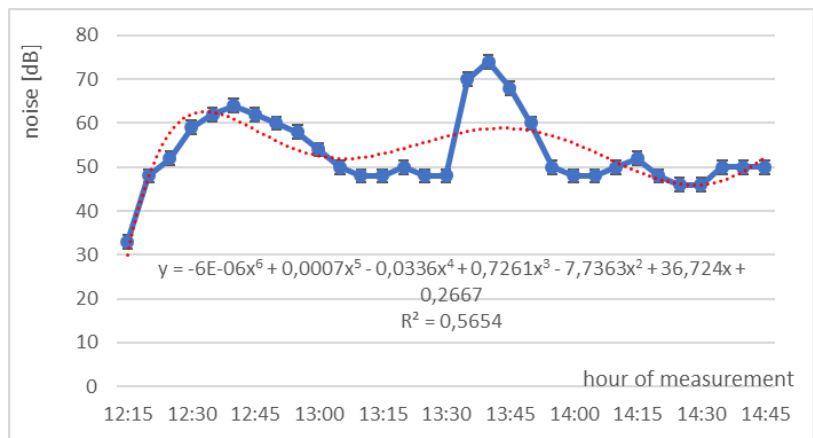

Fig. 5. Measured indoor noise in analysed conference room.

The noise throughout the entire meeting was higher than the one recommended in the conference rooms [32], the sound level was below $50 \mathrm{~dB}$.

After 12:40, a discussion can be observed. The noise level increases (fig. 5) and the concentration of carbon dioxide (fig. 4). The next exciting discussion took place around 13.30. During these hours, a slight increase in relative humidity can also be observed (fig. 3).

Figs. 6 and 7 show the results of a survey. Fig. 6 shows the results of surveys at the beginning of the meeting, while fig. 7 is the results of the questionnaires at the end of the meeting.

At the beginning of the meeting, $25 \%$ of the respondents described all parameters as normal, while at the end of the meeting only $15 \%$ of respondents said this statement.

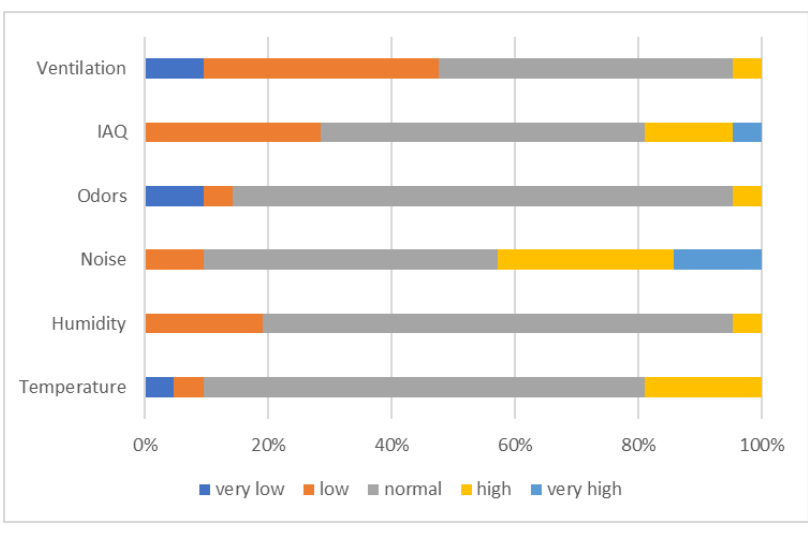

Fig. 6. Total results of survey for tested room at the start of conference proceedings.

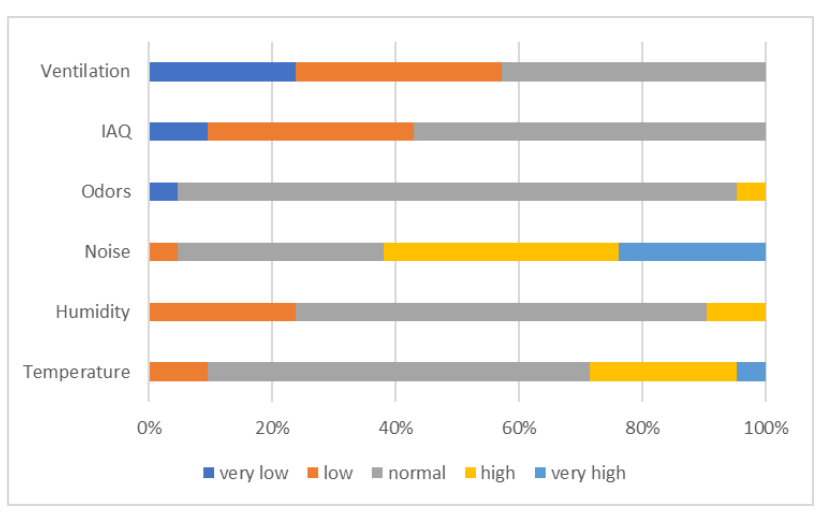

Fig. 7. Total results of survey for tested room at the end of conference proceedings.

Air quality and ventilation were rated the worst. At the beginning of the debate, almost $50 \%$ of respondents weren't satisfied with the ventilation, while at the end of the debate the percentage of dissatisfied persons increased to almost $60 \%$. The same was true for IAQ. At the beginning of the meeting, almost $30 \%$ of the respondents weren't satisfied. At the end of the meeting already $42 \%$ respondents weren't satisfied with IAQ.

Some surprise is the fact that the respondents paid so much attention to the relative humidity of the air, this isn't in accordance with the observations in the literature [5], [33, 34] where it was found, that people control the ventilation into the rooms by thermal comfort rather than air quality. At the beginning of the meeting, less than $20 \%$ of respondents stated that the room is too humid. At the end of the meeting it was already $24 \%$. At the same time, the relative humidity during filling out the questionnaires was $40 \%$ at the beginning and $43 \%$ at the end of the meeting. This value falls within the recommendations contained in the standards [29-31].

The air temperature during the experiment was too low according to the standards [29-31], because it was below $20^{\circ} \mathrm{C}$ throughout the study. At the beginning of the meeting, the respondents said that the temperature was right (85\%). 5\% thought it was low and $10 \%$ thought it was high. At the end of the meeting, only $20 \%$ of the respondents weren't satisfied with the temperature conditions, with $5 \%$ saying that the temperature was low and $15 \%$ considered it high, the temperature was only $19.2^{\circ} \mathrm{C}$. 
The smell by the respondents was practically noticed. At the beginning of $10 \%$, they noted deviations. At the end of the meeting, only $5 \%$.

The parameter that was most important among respondents was noise. As many as $40 \%$ of respondents stated at the beginning of the meeting that the noise is high or very high. At the end of the debate unhappy with the noise was already over $60 \%$. It was probably influenced by the fatigue of conference participants, which was more sensitive and more distracting than at the beginning of the meeting. The noise during measurements usually fluctuated within $50 \mathrm{~dB}$.

\section{Conclusion}

Reducing the need for thermal energy and cooling is crucial for improving the energy efficiency of a building. Modern technology, striving to reduce financial outlays, simultaneously leads to a decrease in air quality.

The air temperature in the room was too low. The respondents didn't notice this. Relative humidity was within normal limits. Nevertheless, $20 \%$ of the respondents described it as too low. At the beginning of the meeting, $30 \%$ of the respondents weren't satisfied with the IAQ, at the end of the debate there were already $42 \%$ of them. The $\mathrm{CO}_{2}$ concentration ranged from $1700-$ $2000 \mathrm{ppm}$ and exceeded the recommended values in standards. Ventilation was assessed from the beginning of the meeting as insufficient by $50 \%$ of respondents, at the end of the meeting $60 \%$. The smell for the respondents wasn't perceptible.

Perform microclimate and comfort analysis in the room, including noise measurements because this parameter was the most noticed by the respondents.

The study has been executed with resources of the S/WBiIŚ/4/14 statutory work financed by the Ministry of Science and Higher Education in Poland and Project cofinanced by the European Regional Development Fund under the Regional Operational Program of the Podlaskie Voivodship for the years 2007-2013 - 1.1. Thanks to the members of the Faculty of Civil and Environmental Engineering for their contribution to the publication.

\section{References}

1. M. Chludzińska, A. Bogdan, Energ. Buildings 126, 373 (2017)

2. T. Jankowski, M. Młynarczyk, JEE 17(5), 114 (2016)

3. A. Leavey, Y. Fu, M. Sha, A. Kutta, Ch. Lu, W. Wang, B. Drake, Y. Chen, P. Biswas, Build. Environ. 85, 287 (2015)

4. N.M. Mateus, G.C. da Graça, Build. Environ. 114, 470 (2017)

5. H. Amai, A. Novoselac, Build. Environ. 109, 101 (2016)

6. A. Witkowska, K. Gładyszewska-Fiedoruk, E3S Web of Conferences 4400189 (2018)
7. L. Stabile, M. Dell'Isola, A. Russi, A. Massimo, G. Buonanno, Sci. Total Environ. 595, 894 (2017)

8. L. Al-Awadi, J. Air Waste Manage. 68(1), 54 (2018)

9. D. Tan, H. Liu, Y. Wu, IJESD 8(6), 425 (2017)

10. P. Spiru, P.L. Simona, Energy Procedia 128, 179 (2017)

11. Z. Tong, Y. Chen, A. Malkawi, G. Adamkiewicz, J.D. Spengler, Environ. Int. 89-90, 138 (2016)

12. M. Hurnik, Energ. Buildings 130, 341 (2016)

13. H. Nowak, L. Nowak, E. Sliwinska, J. Build. Phys. 40(2), 177 (2016)

14. E. Przydróżny, A. Przydróżna, S. Szczęśniak, TSEP 5, 69 (2018)

15. S. Ginestet, D. Marchio, Energ. Buildings 42, 1205 (2010)

16. M. Laska, E. Dudkiewicz, E3S Web of Conferences 22, 00099 (2017)

17. E. Finell, A. Tolvanen, U. Haverinen-Shaughnessy, S. Laaksonen, S. Karvonen, R. Sund, P. Luopa, J. Pekkaneni, T. Ståhlk, Sci. Total Environ. 624, 1504 (2018)

18. M.J. Sulewska, K. Gładyszewska-Fiedoruk, P. Sztulc, Environ. Sci. Pollut. Res. 25, 31205 (2018)

19. X. Zhao, W. Yu, D. Tan, IJESD 8(6), 430 (2017)

20. B. Koelblen, A. Psikuta, A. Bogdan, S. Annaheim, R.M. Rossi, Build. Environ. 130, 200 (2018)

21. D.A. Krawczyk, B. Wądołowska, Energy Procedia 147, 96 (2018)

22. K. Cena, R.J. De Dear, J. Therm. Biol. 26, 409 (2001)

23. M. Rogulski, Energy Procedia 128, 437 (2017)

24. N. Szczepanik-Ścisło, A. Flaga-Maryańczyk, E3S Web of Conferences 44, 00171 (2018)

25. N. Szczepanik-Ścisło, Ł. Ścisło, E3S Web of Conferences 44, 00172 (2018)

26. S. Guergova, A. Dufour, Ageing Res. Rev. 10(1), 80 (2011)

27. I. Ruiz, M. Sprowls, Y. Deng, D. Kulick, H. Destaillats, E.S. Forzani, J. Breath. Res. 12(3), 036012 (2018)

28. R.J. Moffat, ASME J. Fluids Eng. 104, 250 (1982)

29. PN-EN 13779:2008 Ventilation of residential buildings. Requirements for the properties of ventilation and air conditioning

30. ASHRAE Standard 62-2007 Ventilation for acceptable indoor air quality. Atlanta: American Society of Heating and Refrigerating and AirConditioning Engineers Inc.

31. WHO 2000 Air Quality Guidelines for Europe, Second Edition, WHO Regional Office for Europe Copenhagen, European Series, No. 91

32. PN-B-02151-4:2015-06 Building acoustics. Protection against noise in buildings. Part 4: Requirements concerning the conditions of reverberation and speech intelligibility in spaces and research guidelines (In Polish)

33. M. Griffiths, M. Eftekhari, Energ. Buildings 40, 556 (2008)

34. I. Apine, L. Orola, A. Jakovics, IJESD 6(12), 952 (2015) 